Trinity University

Digital Commons @ Trinity

Chemistry Faculty Research

Chemistry Department

$11-2013$

\title{
Effects of Pd on Catalysis by Au: CO Adsorption, CO Oxidation, and Cyclohexene Hydrogenation by Supported Au and Pd-Au Catalysts
}

Timothy Ward

Trinity University

L. Delannoy

Ruth Hahn

Trinity University

Shane Kendell

Trinity University

Christopher J. Pursell

Trinity University, cpursell@trinity.edu

See next page for additional authors

Follow this and additional works at: https://digitalcommons.trinity.edu/chem_faculty

Part of the Chemistry Commons

\section{Repository Citation}

Ward, T., Delannoy, L., Hahn, R., Kendell, S., Pursell, C.J., Louis, C., \& Chandler, B.D. (2013). Effects of Pd on Catalysis by Au: CO Adsorption, CO Oxidation, and Cyclohexene Hydrogenation by Supported Au and Pd-Au Catalysts. ACS Catalysis, 3(11), 2644-2653. doi: $10.1021 / \operatorname{cs} 400569 \mathrm{v}$ 
Authors

Timothy Ward, L. Delannoy, Ruth Hahn, Shane Kendell, Christopher J. Pursell, C. Louis, and Bert D. Chandler 


\title{
Effects of Pd on Catalysis by Au: CO Adsorption, CO Oxidation, and Cyclohexene Hydrogenation by Supported $\mathrm{Au}$ and $\mathrm{Pd}-\mathrm{Au}$ Catalysts
}

Timothy Ward, ${ }^{\dagger, \S}$ Laurent Delannoy, ${ }^{\ddagger}$ Ruth Hahn, ${ }^{\dagger, \perp}$ Shane Kendell, ${ }^{\dagger, \|}$ Christopher J. Pursell, ${ }^{\dagger}$ Catherine Louis, ${ }^{\ddagger}$ and Bert D. Chandler, ${ }^{\dagger} *$

\author{
${ }^{\dagger}$ Department of Chemistry, Trinity University, San Antonio, Texas 78212-7200, United States \\ ${ }^{\ddagger}$ Laboratoire de Réactivité de Surface, UMR 7197 CNRS, Université Pierre et Marie Curie-UPMC, 4 place Jussieu, 75252 Paris Cedex \\ 05, France
}

\begin{abstract}
Incorporating small amounts of $\mathrm{Pd}$ into supported $\mathrm{Au}$ catalysts has been shown to have beneficial effects on selective hydrogenation reactions, particularly 1,3butadiene hydrogenation and the hydrogenation of nitroaromatics, especially $p$-chloronitrobenzene. Appropriate $\mathrm{Pd}$ incorporation enhances hydrogenation activity while maintaining the desirable high selectivity of supported Au catalysts. To better understand this phenomenon, a series of aluminaand titania-supported $\mathrm{Au}$ and dilute $\mathrm{Pd}-\mathrm{Au}$ catalysts were prepared via urea deposition-precipitation. The catalysts were studied with infrared spectroscopy of $\mathrm{CO}$ adsorption, CO

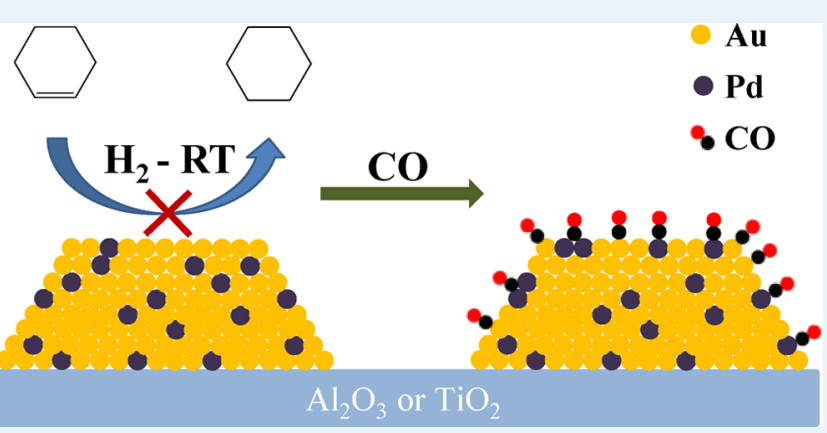
oxidation catalysis, and cyclohexene hydrogenation catalysis with the goal of understanding how $\mathrm{Pd}$ affects the catalytic properties of $\mathrm{Au}$. $\mathrm{CO}$ adsorption experiments indicated a substantial amount of surface $\mathrm{Pd}$ when the catalyst was under $\mathrm{CO}$. Adsorption experiments at various $\mathrm{CO}$ pressures were used to determine $\mathrm{CO}$ coverage; application of the Temkin adsorbate interaction model allowed for the determination of adsorption enthalpy metrics for $\mathrm{CO}$ adsorption on $\mathrm{Au}$. These experiments showed that Pd induces an electronic effect on Au, affecting both the nascent adsorption enthalpy $\left(\Delta H_{0}\right)$ and the change in enthalpy with increasing coverage. This electronic modification had little effect on $\mathrm{CO}$ oxidation catalysis. Michaelis-Menten kinetics parameters showed essentially the same oxygen reactivity on all the catalysts; the primary differences were in the number of active sites. The bimetallic catalysts were poor cyclohexene hydrogenation catalysts, indicating that there is relatively little exposed $\mathrm{Pd}$ when the catalyst is under hydrogen. The results, which are discussed in the context of the literature, indicate that a combination of surface composition and Pd-induced electronic effects on $\mathrm{Au}$ appear to increase hydrogen chemisorption and hydrogenation activity while largely maintaining the selectivities associated with catalysis by Au.
\end{abstract}

KEYWORDS: IR spectroscopy, Pd-Au catalyst, CO heat of adsorption, cyclohexene hydrogenation, Temkin adsorption, CO oxidation, selective hydrogenation

\section{INTRODUCTION}

The high activity of supported gold nanoparticles for catalyzing $\mathrm{CO}$ oxidation at subambient temperatures has been well documented over the past 20 years. ${ }^{1,2}$ The last several years have seen intense interest in applying $\mathrm{Au}$ catalysts to a variety of other reactions, ${ }^{3,4}$ including the water-gas shift reaction, ${ }^{5-7}$ acetylene hydrochlorination, ${ }^{8}$ addition of nucleophiles to acetylenes, ${ }^{9}$ alcohol oxidation to acids and aldehydes, ${ }^{10,11}$ and direct formation of hydrogen peroxide. ${ }^{12}$ Selective hydrogenation reactions have also been examined, particularly for nitroaromatic compounds, ${ }^{13,14}$ 1,3-butadiene, ${ }^{15}$ and acetylene. ${ }^{16,17}$ In most cases, gold catalysts have highly desirable selectivities, but activities are generally lower than classic hydrogenation metals (e.g., Pt, Pd, Ni).

One means of increasing activity and selectivity is to dope the primary component with a second metal. In the particular case of Au-containing catalysts, supported $\mathrm{Pd}-\mathrm{Au}$ catalysts have been, by far, the most widely studied. This is largely due to their use as industrial catalysts in vinyl acetate monomer synthesis, ${ }^{18-20}$ although there is also recent interest in employing $\mathrm{Pd}-\mathrm{Au}$ catalysts in the direct formation of hydrogen peroxide. $^{21,22}$ Interestingly, the functional catalysts appear to be quite different for these two reactions. In vinyl acetate monomer synthesis, the most active and selective catalyst appears to be a fairly dilute arrangement of $\mathrm{Pd}$ atoms in a largely $\mathrm{Au}$ surface, despite $\mathrm{Au} / \mathrm{Pd}$ atomic ratios close to $1 .^{18-20}$ Conversely, direct hydrogen peroxide synthesis appears to be most facile on catalysts composed of a largely Pd surface with $\mathrm{Au}$ in the particle interior $(\mathrm{Au} / \mathrm{Pd}$ atomic ratios $\cong 0.5) .^{22-24}$

Several other reactions have also been recently investigated over $\mathrm{Pd}-\mathrm{Au}$ catalysts, including direct oxidation of primary alcohols, ${ }^{25}$ formic acid dehydrogenation for hydrogen storage, ${ }^{26}$

Received: July 16, 2013

Revised: September 18, 2013

Published: October 1, 2013 
and $\mathrm{C}-\mathrm{H}$ bond activation. ${ }^{27}$ The broad interest in these reactions has led to substantial investigations of the effects of $\mathrm{Au}$ on catalysis by Pd. Although Au has important catalytic properties of its own, there have been relatively few studies of the effects of heterometals on catalysis by Au. In the bulk, Au is largely immiscible with most transition metals ( $\mathrm{Pd}, \mathrm{Cu}$, and $\mathrm{Ag}$ are the notable exceptions), so well-defined alloys have been difficult to prepare, even at the nanoscale. The $\mathrm{Pd}-\mathrm{Au}$ system therefore provides important opportunities to begin to understand the effects of heterometals on $\mathrm{Au}$ catalysis.

Recently, Keane and co-workers studied selective hydrogenation of $p$-chloronitrobenzene over a series of $\mathrm{Au}$ and $\mathrm{Pd}-$ $\mathrm{Au}$ catalysts prepared by deposition-precipitation. ${ }^{14}$ They found that properly prepared dilute $\mathrm{Pd} / \mathrm{Au}$ nanoparticles (less than $10 \mathrm{~mol} \% \mathrm{Pd}$ ) increased hydrogenation activity several fold while maintaining nearly $100 \%$ selectivity for chloroaniline, the desired product. The particle sizes of the catalysts were all similar, so differences in activity could not be attributed to different dispersions. Louis and co-workers followed this study by examining 1,3-butadiene selective hydrogenation and found similar results: small amounts of Pd present in bimetallic particles resulted in increased hydrogenation activity while maintaining the high selectivity associated with monometallic $\mathrm{Au}$ catalysts. ${ }^{28,29}$ They also found substantially enhanced hydrogen chemisorption on the bimetallic catalysts. Hutchings and co-workers studied acetylene hydrochlorination over dilute $\mathrm{Pd}-\mathrm{Au}$ catalysts prepared by coimpregnation and found increased activity when adding small amounts of $\mathrm{Pd}^{30}$ However, they also observed a significant loss in reaction selectivity.

In the current study, we further examine this system with an eye toward understanding the enhanced hydrogenation activity of dilute $\mathrm{Pd}-\mathrm{Au}$ bimetallic catalysts prepared by depositionprecipitation. Specifically, we probe electronic changes to the surface $\mathrm{Au}$ sites by using infrared spectroscopy to measure $\mathrm{CO}$ adsorption isotherms on Au. Applying a Temkin adsorption model yields coverage-dependent heat of adsorption values that are related to $\mathrm{Pd}$-induced electronic changes to the surface $\mathrm{Au}$ atoms. $\mathrm{CO}$ oxidation reaction metrics are also used to evaluate the effects of electronic changes on this reaction, and cyclohexene hydrogenation is used as a probe reaction to evaluate Pd surface concentrations under hydrogenation conditions.

\section{EXPERIMENTAL SECTION}

Materials and Reagents. Water was purified to a resistivity of 17-18 M $\Omega$-cm with a Barnstead Nanopure system. All gases were Praxair or Air Products 5.0 grade cylinders and used without further purification. The $5 \% \mathrm{CO} / \mathrm{He}$ mixture was purchased in an aluminum cylinder to avoid potential contamination by iron carbonyls. Titanium mesh $(30 \times 30$ with a 0.003 in. diameter) was purchased from Unique Wire Weaving Co. and used in IR spectroscopy experiments.

The $\mathrm{Au}, \mathrm{Pd}$, and $\mathrm{Pd}-\mathrm{Au}$ catalysts were prepared on $\mathrm{Al}_{2} \mathrm{O}_{3}$ and $\mathrm{TiO}_{2}$ via urea deposition-precipitation of $\mathrm{HAuCl}_{4}$ and $\mathrm{PdCl}_{2}$ according to previously published procedures. ${ }^{14,28} \mathrm{Au}$ and $\mathrm{Pd}-\mathrm{Au}$ catalysts with $\mathrm{Au} / \mathrm{Pd}$ ratios of $20: 1$ and 10:1 were prepared with a nominal Au loading of $1 \mathrm{wt} \%$. The Pd sample contained $300 \mathrm{ppm} \mathrm{Pd}$, which corresponds to the Pd loading in $\mathrm{Pd}-\mathrm{Au}$ with a ratio of 20:1 ratio. The deposited precursors were reduced under flowing $\mathrm{H}_{2}$ at $300{ }^{\circ} \mathrm{C}$ for $2.5 \mathrm{~h}$ (heating rate $3{ }^{\circ} \mathrm{C} / \mathrm{min}$ ), as previously described. ${ }^{14,28}$ The samples were then transferred to 1 dram screw-cap vials and stored in a desiccator.

Elemental Analysis via ICP-OES. The Au content was determined using a Varian 720-ES inductively coupled plasma optical emission spectrometer (ICP-OES). Approximately 25 $\mathrm{mg}$ of catalyst was accurately weighed in a beaker. Freshly prepared aqua regia $(6 \mathrm{~mL})$ was then added to the sample and allowed to digest at room temperature for $30 \mathrm{~min}$. The sample was then heated slowly to $60^{\circ} \mathrm{C}$ for $2 \mathrm{~h}$, and the resulting solution was filtered into a $25 \mathrm{~mL}$ volumetric flask. The sample was diluted to mark with water and subsequently analyzed. Experimental errors for the method and the spectrometer are typically $<5 \%$.

Infrared Spectroscopy of Adsorbed CO. Infrared spectroscopy experiments were performed as previously reported. ${ }^{31,32}$ Approximately $25 \mathrm{mg}$ of catalyst was pressed into a $30 \times 30 \mathrm{Ti}$ mesh (Unique Wire Weaving Co.). The resulting mesh-supported pellet was placed in an oven and heated in air overnight at $100{ }^{\circ} \mathrm{C}$. After cooling, the meshsupported pellet was mounted into a home-built copper cell and vacuum chamber with a gas-phase optical path length of 1 $\mathrm{cm}$. The entire vacuum chamber was placed in the sample compartment of a Nicolet Magna 550 FT-IR spectrometer and evacuated to a pressure of $<10^{-3}$ Torr for $15 \mathrm{~min}$. All measurements were made at $297 \mathrm{~K}$, and all spectra were referenced to a background spectrum of the catalyst pellet under vacuum prior to the addition of $\mathrm{CO}$. Transmission spectra consisted of 50 scans collected with $8 \mathrm{~cm}^{-1}$ resolution (spectral data spacing $=4 \mathrm{~cm}^{-1}$ ) and were reported in absorbance units.

The gas handling system consisted of a mechanical and diffusion pump, a glass line with stainless steel transfer lines to the sample apparatus, and a Baratron pressure gauge $(P=0-20$ Torr). A liquid nitrogen trap was used to trap out any impurities from the CO tank (UHP grade, from Air Products). The entire gas handling system was rinsed with $\mathrm{CO}$ three times before exposing the sample. After collecting a background spectrum, the sample was exposed to CO (roughly 20 Torr $\mathrm{CO}$ ), and the surface was allowed to equilibrate for 5-10 min; previous work has shown that this is ample time for $\mathrm{CO}$ equilibration on $\mathrm{Au}$ catalysts. ${ }^{31,32}$ An infrared spectrum was recorded, and the pressure in the cell was slowly decreased to the next pressure. After completing an experiment, the sample was evacuated, and the experiment was repeated for a total of two or three adsorption isotherm measurements on a single catalyst sample in a single day. To isolate the $\mathrm{Au}-\mathrm{CO}$ band for the bimetallic samples, spectra were reprocessed by subtracting the lowest pressure spectrum, which included a nearly saturated $\mathrm{Pd}-\mathrm{CO}$ peak.

CO Oxidation Catalysis. The $\mathrm{CO}$ oxidation reactor system consisted of a previously described home-built, laboratory scale, single-pass, plug-flow microreactor. ${ }^{33}$ Feed and catalyst effluent $\mathrm{CO}, \mathrm{CO}_{2}$, and $\mathrm{O}_{2}$ compositions were determined using Siemens Ultramat 23 infrared gas analyzer. Supported catalyst samples (about $10 \mathrm{mg}$ ) were diluted with $\sim 1 \mathrm{~g}$ of 400 mesh silicon carbide (Aldrich) and placed in the microreactor. All reactions were performed at ambient pressure with $1 \% \mathrm{CO}$ in the feed, which was maintained with Porter mass flow controllers. Previously reduced catalysts were pretreated with $10 \% \mathrm{H}_{2} / 10 \% \mathrm{O}_{2} / 80 \% \mathrm{~N}_{2}\left(120 \mathrm{~mL} \mathrm{~min}^{-1}\right)$ for an hour at 250 ${ }^{\circ} \mathrm{C}$. After pretreatment, the furnace was removed,. and the catalyst was allowed to equilibrate under flowing $1 \% \mathrm{CO}+20 \%$ $\mathrm{O}_{2}\left(180 \mathrm{~mL} / \mathrm{min}\right.$ total flow, balance $\left.\mathrm{N}_{2}\right)$ for $1 \mathrm{~h}$. An ice or 
water bath was then placed around the catalyst to control the reaction temperature. Changes in $\mathrm{CO}$ oxidation activity were measured as a function of temperature as well as $\mathrm{CO}$ and $\mathrm{O}_{2}$ feed concentration. All activities were determined by averaging steady state conversion data for $\sim 10 \mathrm{~min}$, usually between 1 and $3 \mathrm{~h}$ after introducing $\mathrm{CO}$ to the activated catalyst. Each activity measurement was performed with a fresh catalyst sample.

Cyclohexene Hydrogenation Catalysis. The catalyst was diluted 20:1 by mass with SiC (Aldrich) and loaded into a glass U-tube. The samples were rereduced in situ, ramping the temperature $5{ }^{\circ} \mathrm{C} / \mathrm{min}$ to $300{ }^{\circ} \mathrm{C}$ and holding for $1 \mathrm{~h}$. The reactor was then cooled to the reaction temperature under flowing $\mathrm{H}_{2}$. The cyclohexene in $\mathrm{H}_{2}$ feed was prepared using a 2stage bubbler. The first stage was held at ambient temperature, and the second stage was maintained at $0{ }^{\circ} \mathrm{C}^{34}$

The reaction was monitored using an SRI $8610 \mathrm{C}$ gas chromatograph with automatic gas sampling valve, $1 \mathrm{~mL}$ sample loop, and FID detector. Products and reactants were quantified using a $\mathrm{SiO}_{2}$ column operated at $260{ }^{\circ} \mathrm{C}$. Peak areas were standardized against external calibration solutions of cyclohexene in hexanes and cyclohexane in cyclohexene. Cyclohexene hydrogenation rates for the $\mathrm{Pd}$ and $\mathrm{Pd}-\mathrm{Au}$ bimetallic catalysts were measured by monitoring conversion as a function of flow rate. Flow rates were measured with a bubble flow meter immediately prior to each injection. Plots of conversion vs inverse space velocity were linear and had $y$ intercepts of $0.02 \%$ or lower. Due to their extremely low activity, rates for the supported Au catalysts were determined from single point experiments at each temperature. In all cases, conversions were below $5 \%$ to maintain differential reactor conditions.

\section{RESULTS}

Six catalysts were characterized with ICP-OES, infrared spectroscopy (CO adsorption), CO oxidation catalysis, and cyclohexene hydrogenation catalysis. Catalyst designations were based on the nominal elemental ratios. The experimental $\mathrm{Au} /$ Pd ratios determined by ICP are close to the values used in the synthesis (Table 1). All of the catalysts in this study have

Table 1. Elemental Analysis Data for Au and Pd-Au Catalysts

\begin{tabular}{lcccc}
\multicolumn{1}{c}{ catalyst } & mass $\% \mathrm{Au}$ & mass $\% \mathrm{Pd}$ & mole $\% \mathrm{Pd}^{a}$ & $\mathrm{Au} / \mathrm{Pd}$ \\
$\mathrm{Au} / \mathrm{TiO}_{2}$ & 0.75 & & & \\
$\mathrm{Pd}_{1} \mathrm{Au}_{20} / \mathrm{TiO}_{2}$ & 0.78 & 0.019 & 4.4 & 22 \\
$\mathrm{Pd}_{2} \mathrm{Au}_{20} / \mathrm{TiO}_{2}$ & 0.77 & 0.039 & 8.5 & 11 \\
$\mathrm{Pd} / \mathrm{TiO}_{2}$ & & 0.043 & 100 & \\
$\mathrm{Au} / \mathrm{Al}_{2} \mathrm{O}_{3}$ & 0.71 & & & \\
$\mathrm{Pd}_{1} \mathrm{Au}_{20} / \mathrm{Al}_{2} \mathrm{O}_{3}$ & 0.70 & 0.015 & 3.9 & 25 \\
$\mathrm{Pd}_{2} \mathrm{Au}_{20} / \mathrm{Al}_{2} \mathrm{O}_{3}$ & 0.80 & 0.037 & 8.0 & 12 \\
$\mathrm{Pd} / \mathrm{Al}_{2} \mathrm{O}_{3}$ & & 0.009 & 100 &
\end{tabular}

${ }^{a}$ Mole percent reflects ratios of the noble metals only.

previously been characterized with transmission electron microscopy and have similar particle sizes, with average particle diameters around 2-3 nm. ${ }^{14,15,28}$

Infrared Spectroscopy of CO Adsorption. The bimetallic catalysts have previously shown enhanced activity and selectivity for chloronitrobenzene ${ }^{14}$ and 1,3-butadiene hydrogenation. ${ }^{28,29}$ To better understand the nature of the enhanced catalysis and probe possible electronic changes to the surface
$\mathrm{Au}$ sites, we characterized the catalysts with infrared transmission spectroscopy of adsorbed $\mathrm{CO}$ at room temperature. Results for $\mathrm{CO}$ adsorption on $\mathrm{Au} / \mathrm{Al}_{2} \mathrm{O}_{3}$ are shown in Figure 1.

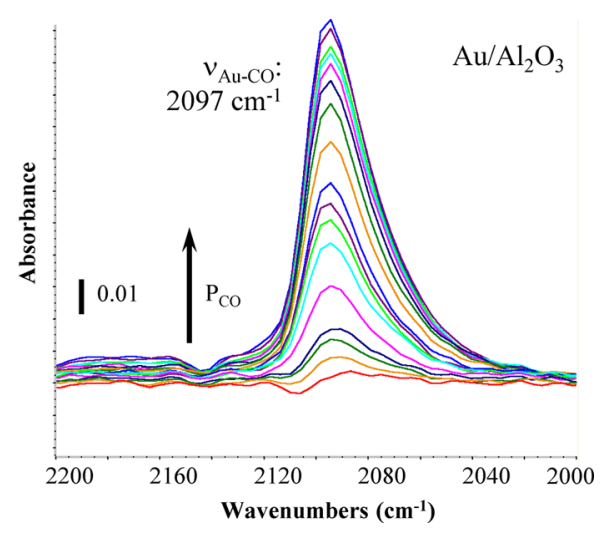

Figure 1. FT-IR spectra of $\mathrm{CO}$ adsorbed on the $\mathrm{Au} / \mathrm{Al}_{2} \mathrm{O}_{3}$ catalyst.

The peak at $\sim 2100 \mathrm{~cm}^{-1}$ is consistent with $\mathrm{CO}$ adsorption on metallic gold, as we and others have previously shown. ${ }^{31,32}$ The monometallic Pd samples did not bind $\mathrm{CO}$ because of surface oxidation during air exposure and pellet drying (see the Experimental Section). In situ reduction was unavailable in our system, so we limit our analysis to the effects of $\mathrm{Pd}$ incorporation into $\mathrm{Au}$ nanoparticles.

Figures 2 and 3 show spectra for $\mathrm{CO}$ adsorbed on the $\mathrm{Pd}_{2} \mathrm{Au}_{20} / \mathrm{Al}_{2} \mathrm{O}_{3}$ and $\mathrm{Pd}_{1} \mathrm{Au}_{20} / \mathrm{Al}_{2} \mathrm{O}_{3}$ catalysts, respectively.

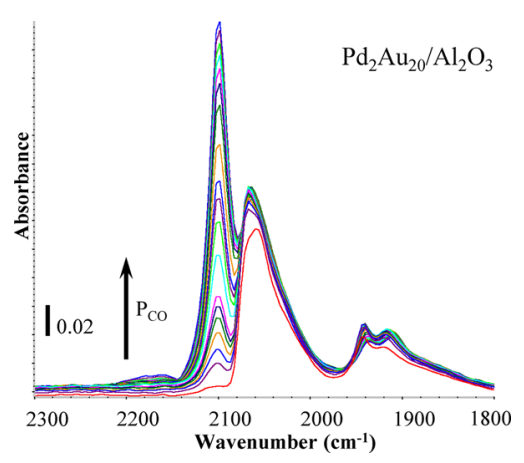

Figure 2. FT-IR spectra of $\mathrm{CO}$ adsorbed on the $\mathrm{Pd}_{2} \mathrm{Au}_{20} / \mathrm{Al}_{2} \mathrm{O}_{3}$ catalyst.

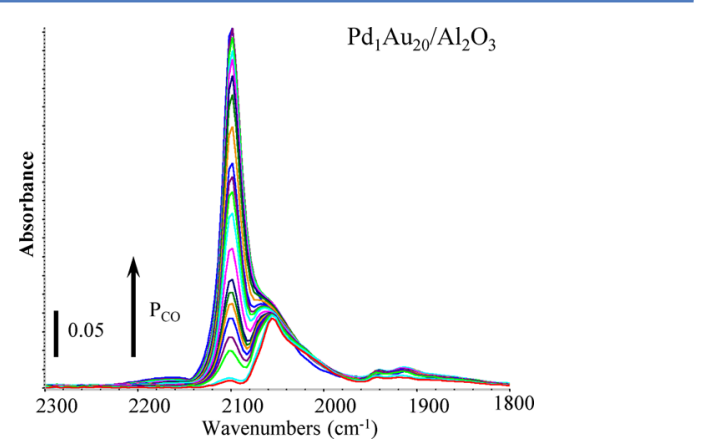

Figure 3. FT-IR spectra of $\mathrm{CO}$ adsorbed on the $\mathrm{Pd}_{1} \mathrm{Au}_{20} / \mathrm{Al}_{2} \mathrm{O}_{3}$ catalyst.

Spectra for the titania-supported samples are similar but are omitted for brevity. Three prominent bands are present. The highest energy band, near $2100 \mathrm{~cm}^{-1}$, is attributed to $\mathrm{CO}$ on 
surface $\mathrm{Au}$ sites. ${ }^{31,32}$ The peaks near 2065 and $1940 \mathrm{~cm}^{-1}$ are attributed to linear and bridge bonded $\mathrm{CO}$ on $\mathrm{Pd}$, respectively. ${ }^{35-37}$ As with the $\mathrm{Au} / \mathrm{Al}_{2} \mathrm{O}_{3}$ sample, the $\mathrm{Au}-\mathrm{CO}$ peak area changes with increasing pressure. The $\mathrm{Pd}-\mathrm{CO}$ peaks, however, show very little change with pressure, indicating that the Pd sites are nearly saturated at the lowest pressure used in this study (10 mTorr).

The spectra of the bimetallic catalysts have several items of note. First, the $\mathrm{CO}$ adsorption experiments are performed exsitu, so the reduced catalyst is exposed to air, and the pellet is dried at $100{ }^{\circ} \mathrm{C}$ in air prior to analysis (see the Experimental Section). Under these mild thermal conditions, the monometallic Pd samples undergo surface oxidation and do not adsorb $\mathrm{CO}$. However, when $\mathrm{Pd}$ is associated with $\mathrm{Au}$ in the bimetallic samples, Pd oxidation does not occur, since surface $\mathrm{Pd}-\mathrm{CO}$ bands are readily observed in the IR spectra. Second, there is a substantial amount of surface Pd under the conditions of the $\mathrm{CO}$ adsorption experiment. Third, the spectra of $\mathrm{CO}$ bound to the bimetallic catalysts are dominated by linearly bound $\mathrm{Pd}-\mathrm{CO}$, rather than the bridge-bonded $\mathrm{CO}$ that dominates the spectra for $\mathrm{CO}$ adsorbed on $\mathrm{Pd}$ nanoparticles and surfaces. ${ }^{35-37}$ Comparing the spectra in Figures 2 and 3, the relative amount of bridging $\mathrm{CO}$ tracks with the amount of $\mathrm{Pd}$ in the sample. That is, the catalyst with more Pd has a greater fraction of bridging sites. These results are fully consistent with previously reported DRIFTS experiments. ${ }^{28,29}$

It is difficult to ascertain potential changes in the $\mathrm{Au}-\mathrm{CO}$ stretching frequency from the raw spectra of $\mathrm{CO}$ adsorbed on the bimetallic catalysts. The linear $\mathrm{Pd}-\mathrm{CO}$ band overlaps with part of the $\mathrm{Au}-\mathrm{CO}$ band; thus, the peak maximum and peak areas include contributions from both spectral bands and must be deconvoluted. To isolate the $\mathrm{Au}-\mathrm{CO}$ band, we reprocessed the spectra, subtracting the spectrum collected at the lowest $\mathrm{CO}$ pressure. This spectrum contains only the Pd-CO band, which is nearly saturated at $10 \mathrm{mT}$ Torr. The resulting spectra, plotted in Figure 4, show essentially the same $\mathrm{CO}$ stretching frequency as the monometallic Au samples $\left(\sim 2100 \mathrm{~cm}^{-1}\right.$, Figure 1); that is, there is no observed shift in the $\mathrm{CO}$ stretching frequency upon $\mathrm{Pd}$ incorporation. The reprocessed spectra also have accurate $\mathrm{Au}-\mathrm{CO}$ peak areas as a function of $\mathrm{CO}$ pressure, which can be used to quantify $\mathrm{CO}$ adsorption on $\mathrm{Au}$ catalysts and extract thermodynamic metrics for $\mathrm{CO}$ binding. ${ }^{32,38,39}$

Details of the data analysis can be found in previous publications. $^{32,38}$ Briefly, the peak areas assigned to CO adsorbed on $\mathrm{Au}$ are used to determine an adsorption isotherm. The adsorption isotherm is then fit using the Temkin adsorbate interaction model. ${ }^{32,38}$ This model invokes a linear change in the adsorption enthalpy with coverage due to Au mediated substrate-substrate interactions.

$$
\Delta G_{\theta, T}=\Delta H_{0}-\theta \delta \Delta H-T \Delta S
$$

The $\Delta G_{\theta, T}$ values can be determined analytically at individual coverages from the adsorption isotherm, allowing one to evaluate an experimentally determined $\Delta G$ as a function of coverage:

$$
\Delta G_{\theta, T}=-R T \ln \left(\frac{\theta}{P(1-\theta)}\right)
$$

The linear portion of the data (usually corresponding to surface coverages between $\theta=0.2$ and 0.8 ) and a previously determined $\Delta S_{\text {ads }}$ value $(-142 \mathrm{~J} /(\mathrm{mol} \mathrm{K})$ for titania supported
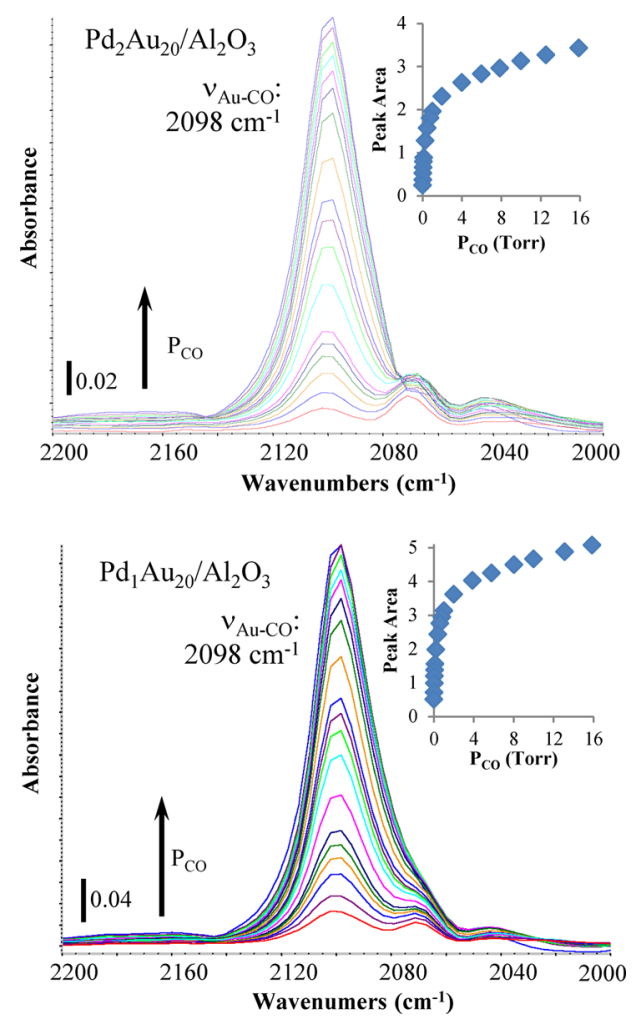

Figure 4. FT-IR spectra of $\mathrm{CO}$ adsorbed to $\mathrm{Au}$ sites on the $\mathrm{Pd}_{2} \mathrm{Au}_{20}$ / $\mathrm{Al}_{2} \mathrm{O}_{3}$ (top panel) and $\mathrm{Pd}_{1} \mathrm{Au}_{20} / \mathrm{Al}_{2} \mathrm{O}_{3}$ (bottom panel) catalysts. The spectrum of $\mathrm{CO}$ bound to the $\mathrm{Pd}$ sites was subtracted from each of the spectra in Figures 2 and 3 to isolate the Au-bound CO.

samples and $-120 \mathrm{~J} /(\mathrm{mol} \mathrm{K})$ for alumina-supported samples) were used to extract two values that describe each catalyst. ${ }^{32}$ The heat of $\mathrm{CO}$ adsorption at zero coverage $\left(\Delta H_{0}\right)$, which is determined from the $y$-intercept of the linear data, describes the nascent binding energy for $\mathrm{CO}$ on the catalyst when no adsorbate interactions are present. The second value, $\delta \Delta H$, describes the change in the adsorption energy from $\theta=0$ to $\theta=$ 1 (i.e., from $\Delta H_{0}$ to $\Delta H_{1}$ ) with full coverage representing saturation of the $\mathrm{CO}$ binding sites. The $\mathrm{CO}$ binding sites are some subset of the total number of surface Au sites, most likely the low coordinate corner and edge atoms. ${ }^{32}$ In the Temkin adsorbate interaction model, this change in adsorption enthalpy is attributed to electronic interactions between the $\mathrm{CO}$ adsorbates and the Au nanoparticles and thus, describes, how the surface electronic properties change with coverage. 32,38

Representative Temkin plots for the catalysts are shown in Figure 5; the extracted $\Delta H_{0}$ and $\delta \Delta H$ values are compiled in Table 2. The data indicate that $\mathrm{Pd}$ incorporation into the catalyst results in a moderate electronic modification of the $\mathrm{Au}$ nanoparticles that results in changes to the $\mathrm{Au}-\mathrm{CO}$ bond strength. The alumina-supported bimetallic catalysts show a $1.5-3 \mathrm{~kJ} / \mathrm{mol}$ increase in $\Delta H_{0}$, indicating stronger $\mathrm{CO}$ binding at low coverage. At the same time, $\delta \Delta H$ doubles relative to the $\mathrm{Au} / \mathrm{Al}_{2} \mathrm{O}_{3}$ sample. The results on the titania-supported catalysts show a similar electronic effect, although the changes in both $\Delta H_{0}$ and $\delta \Delta H$ relative to $\mathrm{Au} / \mathrm{TiO}_{2}$ are attenuated.

CO Oxidation Catalysis. The catalysts were also examined with $\mathrm{CO}$ oxidation catalysis, collecting activity, apparent activation energy, and oxygen dependence data. The monometallic Pd samples were completely inactive for $\mathrm{CO}$ oxidation under these conditions, and the apparent activation energy and 

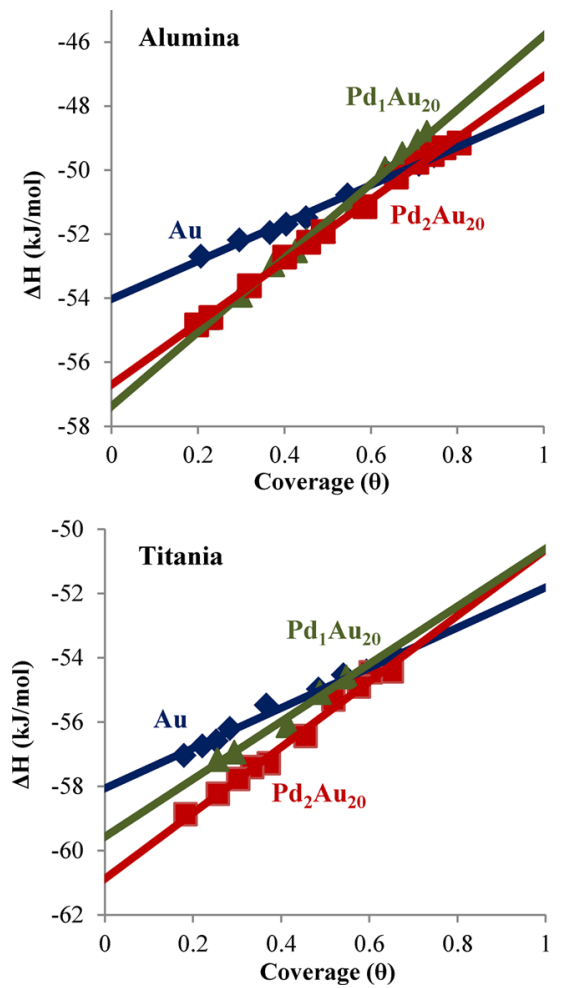

Figure 5. Temkin plots for the alumina- (top panel) and titaniasupported (bottom panel) catalysts.

Table 2. Thermodynamic Metrics for CO Adsorption

\begin{tabular}{lcc}
\multicolumn{1}{c}{ catalyst } & $-\Delta H_{0}(\mathrm{~kJ} / \mathrm{mol})$ & $-\delta \Delta H(\mathrm{~kJ} / \mathrm{mol})$ \\
$\mathrm{Au} / \mathrm{Al}_{2} \mathrm{O}_{3}$ & $54.3 \pm 0.7$ & $5 \pm 2$ \\
$\mathrm{Pd}_{1} \mathrm{Au}_{20} / \mathrm{Al}_{2} \mathrm{O}_{3}$ & $57.8 \pm 0.4$ & $12 \pm 2$ \\
$\mathrm{Pd}_{2} \mathrm{Au}_{20} / \mathrm{Al}_{2} \mathrm{O}_{3}$ & $56.1 \pm 0.1$ & $10 \pm 1$ \\
$\mathrm{Au} / \mathrm{TiO}_{2}$ & $58.1 \pm 0.2$ & $7 \pm 2$ \\
$\mathrm{Pd}_{1} \mathrm{Au}_{20} / \mathrm{TiO}_{2}$ & $59.4 \pm 1.8$ & $10 \pm 1$ \\
$\mathrm{Pd}_{2} \mathrm{Au}_{20} / \mathrm{TiO}_{2}$ & $59.6 \pm 0.1$ & $10 \pm 2$ \\
\hline
\end{tabular}

oxygen reaction order data for $\mathrm{Au} / \mathrm{TiO}_{2}$ and $\mathrm{Au} / \mathrm{Al}_{2} \mathrm{O}_{3}$ (shown in Table 3) are consistent with our previous observations for supported Au catalysts. ${ }^{33,39,40}$ Higher reaction temperatures are required to observe $\mathrm{CO}$ conversion over the alumina-supported

Table 3. CO Oxidation Activity Data for Au and Pd-Au Catalysts

$\begin{array}{ccccccc}\text { catalyst } & \begin{array}{c}\text { rate }^{a} \\ (1 / \mathrm{s})\end{array} & \begin{array}{c}\mathrm{Temp} \\ \left({ }^{\circ} \mathrm{C}\right)\end{array} & \begin{array}{c}E_{\text {app }} \\ (\mathrm{kJ} / \mathrm{mol})\end{array} & \begin{array}{c}\mathrm{O}_{2} \text { rxn } \\ \text { order }\end{array} & \begin{array}{c}\nu_{\max } \\ (1 / \mathrm{s})\end{array} & \begin{array}{c}K_{\mathrm{R}} \\ (\mathrm{atm})\end{array} \\ \begin{array}{c}\mathrm{Au} / \mathrm{TiO}_{2} \\ \mathrm{Pd}_{1} \mathrm{Au}_{20} /\end{array} & 0.19 & -1 & 27.7 & 0.42 & 0.28 & 0.06 \\ \mathrm{TiO}_{2} & 0.28 & -1 & 27.0 & 0.35 & 0.40 & 0.09 \\ \mathrm{Pd}_{2} \mathrm{Au}_{20} / & 0.23 & -1 & 29.2 & 0.35 & 0.28 & 0.08 \\ \mathrm{TiO}_{2} & & & & & & \\ \mathrm{Au}_{\mathrm{Al}_{2} \mathrm{O}_{3}} & 0.16 & 24 & 31.0 & 0.44 & 0.26 & 0.12 \\ \mathrm{Pd}_{1} \mathrm{Au}_{20} / & 0.05 & 24 & 28.5 & 0.38 & 0.06 & 0.08 \\ \mathrm{Al}_{2} \mathrm{O}_{3} & & & & & & \\ \mathrm{Pd}_{2} \mathrm{Au}_{20} / & 0.08 & 24 & 33.2 & 0.42 & 0.13 & 0.11 \\ \mathrm{Al}_{2} \mathrm{O}_{3} & & & & & & \end{array}$

${ }^{a} \mathrm{P}\left(\mathrm{O}_{2}\right)=0.2 \mathrm{~atm}$, average of 2 runs on 2 different samples. Rates are expressed as mole of $\mathrm{CO}$ converted per total mole Au per second. Note that the $\mathrm{TiO}_{2}$ samples are more active because their kinetics were determined at a lower temperature. catalysts, indicating that the titania-supported catalysts are more active for $\mathrm{CO}$ oxidation.

The oxygen pressure data can also be evaluated with double reciprocal plots using a Michaelis-Menten type treatment. ${ }^{33}$ This treatment is used to provide a means of extracting quantitative parameters that describe $\mathrm{O}_{2}$ reactivity for individual gold catalysts; it is not intended to capture all of the molecular complexity of every elementary step in the reaction mechanism. A full derivation of this treatment has been previously published. ${ }^{33}$ Briefly, a simple characterization mechanism (Scheme 1), which has also been suggested by DFT calculations, ${ }^{41,42}$ is used to describe the reaction.

Scheme 1

$$
\begin{aligned}
& \mathrm{Au}+\mathrm{CO} \stackrel{\text { fast }}{\rightleftarrows} \mathrm{Au}-\mathrm{CO} \\
& \mathrm{A}^{*}+\mathrm{O}_{2} \underset{\mathrm{k}_{-1}}{\stackrel{\mathrm{k}_{1}}{\gtrless}} \mathrm{A}^{*}-\mathrm{O}_{2} \\
& \mathrm{~A}^{*}-\mathrm{O}_{2}+\mathrm{Au}-\mathrm{CO} \stackrel{\mathrm{k}_{2}}{\longrightarrow} \mathrm{A} *-\mathrm{O}+\mathrm{Au}+\mathrm{CO}_{2} \\
& \mathrm{~A}^{*}-\mathrm{O}+\mathrm{Au}-\mathrm{CO} \stackrel{\text { fast }}{\longrightarrow} \mathrm{A}^{*}+\mathrm{Au}+\mathrm{CO}_{2}
\end{aligned}
$$

The characterization mechanism in Scheme 1 is intentionally nonspecific regarding the nature of the active site for $\mathrm{O}_{2}$ activation. Structurally, it requires only that $\mathrm{O}_{2}$ is bound and activated someplace on the catalyst close to a $\mathrm{Au}$ surface atom capable of binding $\mathrm{CO}$. Beyond this, the characterization mechanism requires no further assumptions regarding the nature or structure of the active site. The assumption that oxygen is bound at or near a $\mathrm{Au}-\mathrm{CO}$ site is widely agreed upon in the literature, although debate remains regarding the nature and structure of the active site. ${ }^{1,2,43}$ One of the goals of this work is to glean some insight into how Pd might affect the number and nature of active sites; it is therefore prudent to make as few structural and kinetic assumptions about the active site(s) as possible.

In the key kinetic steps of the characterization mechanism, oxygen is bound at an active site $\left(\mathrm{A}^{*}\right)$ and then reacts with readily available $\mathrm{CO}$ to produce $\mathrm{CO}_{2}$. Subsequent steps to produce a second equivalent of $\mathrm{CO}_{2}$ and regenerate the active site are considered fast steps after the rate-determining step in this kinetic model, and are therefore kinetically unobservable. This is consistent with the widely held belief that $\mathrm{O}_{2}$ activation is rate-determining in $\mathrm{CO}$ oxidation over Au. ${ }^{2,44}$ Similarly, this mechanism is not intended to include the details of oxygen activation, as many reasonable possibilities exist for the actual rate-determining step (e.g., oxygen migration, $\mathrm{O}-\mathrm{O}$ bond scission, $\mathrm{O}$ atom transfer to $\mathrm{CO}$, etc.). The characterization mechanism is therefore an intentionally reductionist approach designed to help foster the extraction of chemically meaningful reaction metrics. It is not intended to advance specific mechanistic possibilities or make a priori assumptions regarding the nature of the active site.

Applying a typical kinetic derivation employing the steadystate approximation to Scheme 1 yields the following expression:

$$
\frac{1}{\nu_{\mathrm{rxn}}}=\frac{K_{\mathrm{R}}}{\nu_{\max }}\left(\frac{1}{P_{\mathrm{O}_{2}}}\right)+\frac{1}{\nu_{\max }}
$$

where $\nu_{\mathrm{rxn}}$ is the measured reaction rate, and 


$$
\nu_{\max }=k_{2} \theta_{\mathrm{CO}}\left[\mathrm{A}^{*}\right]_{\mathrm{T}}
$$

and

$$
K_{\mathrm{R}}=\frac{k_{-1}+k_{2} \theta_{\mathrm{CO}}}{k_{1}}
$$

We note that a similar set of equations can be derived using a Langmuir-Hinshelwood mechanism, although this requires some additional assumptions. ${ }^{33}$ In eqs 3 and $5, \theta_{\mathrm{CO}}$ designates the coverage of the $\mathrm{CO}$ binding sites, which are a subset of the total $\mathrm{Au}$ surface sites, and $\left[\mathrm{A}^{*}\right]_{\mathrm{T}}$ is the total number of active sites. The total number of active sites is also assumed to involve a subset of the total number of surface Au sites. $K_{\mathrm{R}}$ and $\nu_{\max }$ are descriptive kinetic parameters comparable to those employed in enzyme kinetics. ${ }^{45}$ Analogous to the Michaelis-Menten constant, $K_{\mathrm{R}}$ is a measure of the reactivity or instability of adsorbed $\mathrm{O}_{2}\left(\mathrm{cf}\right.$. $\left.\mathrm{A}^{*}-\mathrm{O}_{2}\right)$. Similarly, $\nu_{\max }$ depends both on the intrinsic reaction barrier and the number of active sites. This kinetic treatment has been previously published and has been shown to well describe kinetic data for $\mathrm{CO}$ oxidation over several $\mathrm{Au}^{33}$ and bimetallic NiAu catalysts, ${ }^{40}$ as well as a series of $\mathrm{NaBr}$-poisoned Au catalysts. ${ }^{39}$

The activity data shown in Figure 6 and Table 3 indicate that $\mathrm{Pd}$ incorporation has little impact on $\mathrm{CO}$ oxidation rates. The

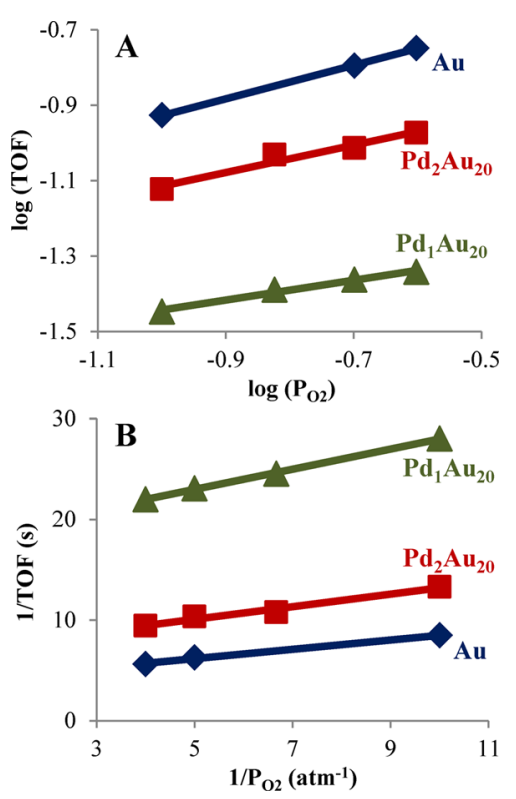

Figure 6. Kinetics plots for $\mathrm{CO}$ oxidation catalysis over the alumina supported catalysts: (A) $\mathrm{O}_{2}$ reaction order and (B) double reciprocal plots used to determine $K_{\mathrm{R}}$ and $\nu_{\max }$.

$\mathrm{O}_{2}$ reaction orders, apparent activation energies $\left(E_{\text {app }}\right)$, and $K_{\mathrm{R}}$ values are potentially the most sensitive parameters to electronic modification of the catalyst. However, all of these parameters are essentially unaffected by $\mathrm{Pd}$ incorporation, indicating that the presence of Pd does not substantially affect the reactivity of gold in $\mathrm{CO}$ oxidation catalysis. In particular, the $K_{R}$ values, which provide a semiquantitative measure of each catalyst's ability to activate oxygen, are relatively consistent for the catalysts. For comparison, bimetallic $\mathrm{Ni}-\mathrm{Au}$ catalysts showed up to a 40 -fold increase in $K_{\mathrm{R}}$, albeit $\mathrm{Ni} / \mathrm{Au}$ ratios $>1$ were required for substantial modification of the reaction kinetics. $^{40}$ For these dilute $\mathrm{PdAu}$ catalysts, it does not appear that the electronic effects observed in the $\mathrm{CO}$ adsorption experiments are sufficient to modify $\mathrm{CO}$ oxidation catalysis.

It may also be possible that $\mathrm{Pd}$ is oxidized under the reaction conditions, changing the electronic interactions; however, as mentioned above, the Pd in the PdAu catalysts seem to be more resistant to oxidation in air at room temperature than monometallic Pd. Unfortunately, the low Pd content of the samples makes this extremely difficult to verify. Because the $K_{\mathrm{R}}$ values are consistent, the changes in $\nu_{\max }$ suggest that the differences in $\mathrm{CO}$ oxidation catalysis are primarily due to differences in the number of active sites from one catalyst to the next. All of the catalysts have been previously characterized and found to have particle sizes in the $2-3 \mathrm{~nm}$ range; ${ }^{14,28,29}$ however, the particle sizes are not strictly identical, which can result in differences in the number of active sites. Further, the number of active sites is closely tied to the in situ production of surface carbonates during the reaction which can poison the metal-support interface. ${ }^{46}$

Cyclohexene Hydrogenation. Supported gold catalysts are notoriously poor alkene hydrogenation catalysts, evidenced by investigations into their potential as catalysts for the selective hydrogenation of alkynes or alkadienes to alkenes. ${ }^{14,16,17}$ Palladium, on the other hand, is an excellent alkene hydrogenation catalyst; consequently, alkene hydrogenation reactions provide a method for probing catalyst surface compositions under hydrogenation reaction conditions. ${ }^{47}$ Catalysts with surface compositions that are largely $\mathrm{Au}$ are expected to behave similarly to monometallic $\mathrm{Au}$, whereas catalysts that have substantial amounts of Pd on the surface are expected to have reactivity similar to $\mathrm{Pd}$. Cyclohexene hydrogenation activity data are presented in Table 4 . Because

Table 4. Cyclohexene Hydrogenation Activity Data for Au and Pd-Au Catalysts

\begin{tabular}{lcclll}
\multicolumn{1}{c}{ catalyst } & $\begin{array}{c}\text { temp } \\
\left({ }^{\circ} \mathrm{C}\right)\end{array}$ & $\begin{array}{c}\text { rate }^{a} \\
(1 / \mathrm{min})\end{array}$ & \multicolumn{1}{c}{ catalyst } & $\begin{array}{c}\text { temp } \\
\left({ }^{\circ} \mathrm{C}\right)\end{array}$ & $\begin{array}{c}\text { rate }^{a} \\
(1 / \mathrm{min})\end{array}$ \\
$\mathrm{Au} / \mathrm{TiO}_{2}$ & 275 & $<1$ & $\mathrm{Au} / \mathrm{Al}_{2} \mathrm{O}_{3}$ & 275 & $<1$ \\
$\mathrm{Pd}_{1} \mathrm{Au}_{20} / \mathrm{TiO}_{2}$ & 98 & 2.3 & $\mathrm{Pd}_{1} \mathrm{Au}_{20} / \mathrm{Al}_{2} \mathrm{O}_{3}$ & 98 & 4.0 \\
$\mathrm{Pd}_{2} \mathrm{Au}_{20} / \mathrm{TiO}_{2}$ & 98 & 2.8 & $\mathrm{Pd}_{2} \mathrm{Au}_{20} / \mathrm{Al}_{2} \mathrm{O}_{3}$ & 98 & 19 \\
$\mathrm{Pd} / \mathrm{TiO}_{2}$ & 11 & 8.4 & $\mathrm{Pd} / \mathrm{Al}_{2} \mathrm{O}_{3}$ & 28 & 180 \\
$\mathrm{Pd} / \mathrm{TiO}_{2}$ & 20 & 19 & & & \\
$\mathrm{Pd} / \mathrm{TiO}_{2}$ & 23 & 26 & $\mathrm{Pd} / \mathrm{TiO}_{2}$ & 98 & $\sim 5400^{b}$
\end{tabular}

${ }^{a}$ Rate expressed in moles cyclohexane per mole metal per minute. ${ }^{b}$ Estimated from Arrhenius plot.

catalyst activity varied dramatically with composition, we were unable to evaluate all of the catalysts at a single temperature. As expected from previous studies, the monometallic Au catalysts were exceptionally poor alkene hydrogenation catalysts, showing no activity until nearly $300{ }^{\circ} \mathrm{C} .{ }^{15,49}$ The monometallic $\mathrm{Pd}$ catalysts were highly active, and the bimetallic PdAu catalysts begin to show activity around $100{ }^{\circ} \mathrm{C}$, intermediate between the two monometallic catalysts.

\section{DISCUSSION}

The $\mathrm{Au}$ and $\mathrm{Pd}-\mathrm{Au}$ catalysts in this study have previously been characterized with transmission electron microscopy; all of the catalysts were found to have similar particle sizes (2-3 $\mathrm{nm}){ }^{14,15,28}$ The differences in the total metal surface area are therefore relatively small and cannot explain the large differences in 1,3 -butadiene $e^{28}$ and $p$-chloronitrobenzene ${ }^{14}$ hydrogenation activity between the $\mathrm{Au}$ and $\mathrm{Pd}-\mathrm{Au}$ catalysts. 
Our study used CO adsorption, CO oxidation, and cyclohexene hydrogenation to probe the surface of the metal nanoparticles and to provide additional insight into the bimetallic catalysts. The key question that we would like to understand is: Why does Pd incorporation increase selective hydrogenation activity while largely maintaining the selectivity associated with monometallic Au catalysts?

To frame the discussion that follows, we offer two limiting cases that might explain these results and highlight the merits and shortcomings of each model. The first possibility is that $\mathrm{Pd}$ is present on the surface of the bimetallic nanoparticles and that this surface Pd activates $\mathrm{H}_{2}$ more efficiently than Au. For clarity, we will refer to this as the "surface Pd" model. Since hydrogen dissociation has been suggested to be the rate-determining step in butadiene hydrogenation over $\mathrm{Au},{ }^{15}$ the higher rates might be explained by the presence of this surface Pd. The second possible explanation is that incorporating $\mathrm{Pd}$ into $\mathrm{Au}$ particles induces some electronic change to the surface $\mathrm{Au}$ atoms and that the modified $\mathrm{Au}$ surface catalyzes the reaction more quickly than the monometallic Au catalysts. We will refer to this limiting case as the "electronic modification" model.

We consider the "electronic modification" model first. This explanation is attractive because the $\mathrm{CO}$ heat of adsorption experiments show that an electronic influence of $\mathrm{Pd}$ on $\mathrm{Au}$ does, indeed, exist: incorporating Pd into the catalyst causes a marked change in the metrics for the heat of adsorption of $\mathrm{CO}$ on $\mathrm{Au}$ (Table 2). Similar electronic effects (net electron donation from $\mathrm{Pd}$ to $\mathrm{Au}$ ) have been reported by several research groups. ${ }^{48-52}$ Baber, Tierney, and Sykes used a variety of STM techniques to show that both surface and subsurface $\mathrm{Pd}$ atoms were depleted of charge in $\mathrm{Pd} / \mathrm{Au}(111)$ near surface alloys. ${ }^{48}$ Williams, Monnier, and co-workers collected XPS data on $\mathrm{Pd}-\mathrm{Au}$ catalysts prepared via electroless deposition; their data also suggested net electron transfer from $\mathrm{Pd}$ to $\mathrm{Au} .{ }^{49,50} \mathrm{On}$ the basis of XPS and XANES data, Marx and Baiker concluded that the $\mathrm{Au} 5 \mathrm{~d}$ density of states showed greater filling and shifted toward the Fermi level upon the formation of $\mathrm{Pd}-\mathrm{Au}$ nanoparticles. ${ }^{51}$ They were able to more conclusively attribute these changes to alloying with $\mathrm{Pd}$ by showing that the magnitude of changes in the bimetallic nanoparticles was much greater than changes associated with particle size effects or differing metal-support interactions. ${ }^{51}$ Zhang, Li, and coworkers also used changes in the stretching frequency of $\mathrm{CO}$ adsorbed onto surface Pd atoms to suggest charge transfer from Pd to Au. ${ }^{52}$

The CO heat of adsorption data reported here are consistent with these findings from the literature. The heat of adsorption of other adsorbates, including hydrogen, is expected to scale with $\mathrm{CO}$ heat of adsorption. ${ }^{41,53,54}$ The observation of increased $\mathrm{H}_{2}$ chemisorption (higher $\mathrm{H}$ /metal ratios) measured on the bimetallic catalysts ${ }^{14}$ is therefore also consistent with the electronic effect. Since hydrogen activation has been suggested to be the rate-determining step in Au-catalyzed hydrogenations, ${ }^{15}$ this model is attractive because it provides a straightforward explanation for why the selectivity associated with $\mathrm{Au}$ is maintained while activity is increased upon $\mathrm{Pd}$ incorporation. Namely, surface Au atoms are the active sites in both the mono- and bimetallic catalysts.

The "surface Pd" model suggests that the incorporated Pd is present on the catalyst surface and functions to help activate $\mathrm{H}_{2}$ and increase the hydrogen coverage during hydrogenation reactions. Although the $\mathrm{CO}$ adsorption data show an electronic effect of $\mathrm{Pd}$ on the $\mathrm{Au}$ sites, the spectra include a substantial contribution from Pd-CO interactions (Figures 2 and 3). This provides the strongest evidence for the role of the "surface Pd" model in explaining the enhanced 1,3-butadiene hydrogenation activity. Pd is well-known to be a far superior hydrogenation catalyst, so even very small amounts of surface Pd might increase the hydrogenation activity relative to $\mathrm{Au}$. The IR data also indicate that as $\mathrm{Pd}$ becomes more and more dilute in $\mathrm{Au}$, the surface $\mathrm{Pd}$ atoms have a greater propensity to become isolated from one another on the surface, appearing as surface monomers. $^{55-57}$

This data must be considered carefully, however. Comparing the $\mathrm{CO}$ band intensities is difficult because extinction coefficients depend on surface roughness, the angle of the vibrating dipole from the surface normal, and distancedependent dipole coupling effects. ${ }^{58-60}$ Further, these effects are metal-dependent. For example, Vannice and Wang found that, for $\mathrm{CO}$ adsorbed on $\mathrm{Pt}$, higher frequency linear modes have higher extinction coefficients than do lower frequency bridging modes. ${ }^{61}$ Vannice and Wang also reported that the opposite was true for $\mathrm{Pd}^{62}$ It is therefore difficult to make a quantitative evaluation of the surface composition on the basis of the IR intensities. Nevertheless, the trend as the catalyst Pd content decreases is the important observation. As the nanoparticles and surfaces become more dilute in $\mathrm{Pd}$, the $\mathrm{Pd}$ is more likely to be found as isolated monomers surrounded by Au. At very dilute limits, one would expect there to be few if any $\mathrm{Pd}$ dimers on the nanoparticle surface; this has been observed by several researchers for the PdAu system. ${ }^{36,63,64}$ Therefore, the "surface Pd" model provides a good potential explanation for the increased hydrogenation activity, but the relative influence of surface Pd dimers is unclear, particularly their role in affecting reaction selectivity.

Ultimately, the relative influence of these two models depends on the surface composition under hydrogenation conditions. We therefore consider the possibility that the surface may be substantially different under $\mathrm{CO}$ and hydrogen atmospheres. Goodman's group used low-energy ion scattering spectroscopy (LEIS) to show that $\mathrm{Pd}-\mathrm{Au}$ alloy films are thermodynamically driven to form stable alloys with surfaces that are highly enriched in Au under ultrahigh vacuum (UHV) conditions. ${ }^{35}$ Several groups have reported that $\mathrm{CO}$ can induce substantial structural changes to $\mathrm{Pd}-\mathrm{Au}$ nanoparticles, with the strong $\mathrm{Pd}-\mathrm{CO}$ interactions providing a driving force to draw $\mathrm{Pd}$ to the nanoparticle surface. ${ }^{28,29,65,66}$ Previous studies on the same catalysts as in the present study showed that the DRIFTS spectra evolved over time under $\mathrm{CO}$, suggesting that the surface composition does, indeed, change to increase the number of surface $\mathrm{Pd}$ atoms under $\mathrm{CO} .^{28}$

Given the evolution of the catalyst surface under $\mathrm{CO}$ and the uncertainty in the kinetics of this process, it is difficult to accurately evaluate the surface composition of the catalyst under hydrogenation conditions. However, Goodman's LEIS studies, ${ }^{35}$ which have essentially no metal-adsorbate interactions due to the UHV conditions, provide a baseline for considering the catalyst surface structure under reactive gases. Relative to CO, hydrogen has a substantially smaller heat of adsorption on $\mathrm{Pd}^{67}$ therefore, hydrogen likely induces a smaller perturbation to the catalyst surface composition from the Au enrichment observed in UHV studies. It is likely that the surface contains less Pd than is observed under $\mathrm{CO}$ and that lower surface $\mathrm{Pd}$ catalysts will have a greater fraction of the $\mathrm{Pd}$ present as monomeric surface species. The cyclohexene hydrogenation experiments were performed specifically to 
evaluate the surface Pd composition; unfortunately, the results from these experiments are ultimately ambiguous.

In understanding these differences, it is important to make a clear distinction between the substrates involved in the hydrogenation reactions. To be clear, we refer to alkenes exclusively as monoalkenes, such as propylene and cyclohexene. Polyunsaturated molecules and dienes, such as 1,3-butadiene, are considered to be chemically distinct species with relatively different chemistries and affinities for the metal catalyst. For cyclohexene hydrogenation over $\mathrm{Au}$, alkene binding rather than hydrogen activation or coverage appears to be rate-determining. This experimental fact is evidenced in this study: the monometallic $\mathrm{Au}$ catalysts described here are inactive for gas phase cyclohexene hydrogenation below $250{ }^{\circ} \mathrm{C}$ (Table 4), yet are active for butadiene hydrogenation at temperatures as low as $100{ }^{\circ} \mathrm{C}$. We note that liquid phase cyclohexene hydrogenation over gold catalysts has been observed at lower temperatures under much higher hydrogen pressures. ${ }^{68}$

Palladium, on the other hand, easily binds alkenes; thus, cyclohexene hydrogenation can be used to evaluate the amount of $\mathrm{Pd}$ on the surface during hydrogenation conditions. Cyclohexene hydrogenation activity on the bimetallic catalysts is between the activity of the monometallic Pd and Au catalysts (Table 4). The bimetallics are substantially more active than monometallic $\mathrm{Au}$, suggesting that there is some $\mathrm{Pd}$ on the surface. At the same time, the bimetallics are, relative to $\mathrm{Pd}$, extraordinarily inactive. We have tried to measure the cyclohexene hydrogenation activity for the $\mathrm{Pd} / \mathrm{TiO}_{2}$ catalyst at $98{ }^{\circ} \mathrm{C}$, where the $\mathrm{Pd}-\mathrm{Au}$ activity is observed. Even with highly diluted samples $(\sim 1 \mathrm{mg}$ of catalyst) we cannot get conversions low enough to measure a reaction rate. On the basis of a temperature study near room temperature with the $\mathrm{Pd} / \mathrm{TiO}_{2}$ catalyst, and extrapolating an Arrhenius relationship to $98{ }^{\circ} \mathrm{C}$, the estimated Pd activity is roughly 4 orders of magnitude higher than in the bimetallic catalysts.

This allows for some qualitative comparisons between the catalysts. If all of the cyclohexene hydrogenation activity is attributed to surface $\mathrm{Pd}$ atoms having comparable activity to monometallic $\mathrm{Pd}$, then the surface fraction of $\mathrm{Pd}$ in the bimetallic catalysts would be roughly one surface $\mathrm{Pd}$ atom for every 1000 surface $\mathrm{Au}$ atoms. This corresponds to approximately one surface $\mathrm{Pd}$ atom per nanoparticle (a $3 \mathrm{~nm} \mathrm{Au}$ particle contains roughly 1000 atoms). Although there are difficulties comparing extinction coefficients for $\mathrm{CO}$ in the IR data, the fraction of surface $\mathrm{Pd}$ atoms suggested by the cyclohexene hydrogenation data is far below what we can observe by IR spectroscopy and is inconsistent with the observation of Pd dimers.

The cyclohexene hydrogenation results therefore support the conclusion that the bimetallic catalysts have substantially less surface Pd under hydrogenation conditions than when exposed to CO. This estimation, however, was predicated on a simple model in which the surface Pd in the bimetallic catalysts has activity comparable to the surface $\mathrm{Pd}$ in a monometallic $\mathrm{Pd}$ nanoparticle. The very low cyclohexene hydrogenation activity of the bimetallic catalysts suggests that the surface Pd may be somewhat less active in the bimetallic catalysts (relative to monometallic Pd catalysts). This is consistent with a net electron transfer from $\mathrm{Pd}$ to $\mathrm{Au}$ observed in the $\mathrm{CO}$ binding experiments.

Finally, the two models presented ("electronic modification" and "surface Pd") represent two limiting cases that explain why the bimetallic catalysts are more active hydrogenation catalysts than monometallic Au catalysts and yet maintain the selectivity associated with $\mathrm{Au}$. The reality likely lies somewhere between the two extreme models. For example, the data is consistent with a case that, under hydrogenation conditions, a small amount of surface Pd is present and serves to dramatically increase hydrogen activation rates without providing a substantial number of sites for binding other substrates. The electronic effect of the Pd on Au then may help to stabilize surface hydrogen and increase the hydrogen surface coverage, thus speeding up reaction.

The presence of small amounts of surface $\mathrm{Pd}$ under hydrogenation conditions is entirely consistent with the selectivity patterns observed during 1,3-butadiene hydrogenation. ${ }^{28}$ In butadiene hydrogenation over these $\mathrm{Pd}-\mathrm{Au}$ catalysts, the diene is nearly completely converted to alkenes before alkene hydrogenation begins to form alkanes. ${ }^{28}$ Monometallic Au catalysts, on the other hand, do not bind alkenes and hydrogenate alkenes at the moderate temperatures employed in dienes' or alkynes' hydrogenation. ${ }^{16,28}$ As in the cyclohexene hydrogenation studies reported here, the alkene hydrogenation activity of the bimetallic catalysts lies somewhere between the hydrogenation activity of the monometallic catalysts. Beyond that, it is difficult to accurately attribute how much of this effect is due to the electronic modification of $\mathrm{Au}$ and how much is due to the dilution of a small amount of Pd on the catalyst surface; it is likely a combination of both.

The combination of the two models is also attractive because it explains another interesting observation for the bimetallic catalysts. Monometallic Pd catalysts undergo rapid surface oxidation in ambient air, so $\mathrm{CO}$ adsorption experiments must be performed after in situ reduction, with oxygen being excluded. We cannot observe $\mathrm{CO}$ adsorption onto monometallic Pd catalysts with the IR cell used in this study, presumably because of the presence of surface $\mathrm{PdO}$, which prevents $\mathrm{CO}$ from adsorbing on the $\mathrm{Pd}$. However, the bimetallic catalysts show substantial $\mathrm{CO}$ adsorption on $\mathrm{Pd}$, even after air contact (see Experimental). This indicates that the $\mathrm{Au}$ acts to protect the $\mathrm{Pd}$ from oxidation by atmospheric oxygen. This could be due to a combination of most of the Pd being present as subsurface $\mathrm{Pd}$ (consistent with the low hydrogenation rates and $\mathrm{CO}$ pulling $\mathrm{Pd}$ to the surface). An electronic influence of $\mathrm{Au}$ on $\mathrm{Pd}$ might also weaken surface $\mathrm{Pd}-\mathrm{O}$ interactions, but it is difficult to envision that this would be significant enough to prevent surface Pd oxidation.

The combined models explanation is also attractive because it is consistent with the low cyclohexene hydrogenation activity of the surface Pd. Even if one attributes the cyclohexene hydrogenation entirely to a small fraction of surface Pd atoms, the activity on a per surface Pd basis is more than an order of magnitude lower than for the monometallic Pd catalyst. This suggests that the interactions with $\mathrm{Au}$ lower the Pd activity through a combination of the electronic interactions and the dilution in $\mathrm{Au}$, which reduces the amount of contiguous $\mathrm{Pd}$ atoms. Further, Hwang's group has performed a number of computational studies examining the reactivity of local $\mathrm{Pd}-\mathrm{Au}$ nanostructures ( $\mathrm{Pd}$ monomers, dimers, trimmers, etc.). They have consistently concluded that isolated Pd monomers have reactivities substantially different from other Pd structures in $\mathrm{Pd}-\mathrm{Au}$ alloys. ${ }^{69-71}$ Our results are entirely consistent with their calculations and provide a reasonable explanation for the relatively low cyclohexene hydrogenation activity of these catalysts. 


\section{CONCLUSIONS}

A series of alumina and titania supported $\mathrm{Au}$ and dilute $\mathrm{Pd}-\mathrm{Au}$ catalysts were studied with infrared spectroscopy of $\mathrm{CO}$ adsorption, CO oxidation catalysis, and cyclohexene hydrogenation catalysis with the goal of understanding how Pd affects the catalytic properties of $\mathrm{Au}$. $\mathrm{CO}$ adsorption experiments indicated a substantial amount of surface Pd when the catalyst was under CO. These experiments also showed that Pd induces an electronic effect on $\mathrm{Au}$, as the nascent heat of adsorption increased upon $\mathrm{Pd}$ incorporation. In addition, $\mathrm{Pd}$ incorporation affected the coverage dependence of the $\mathrm{CO}$ adsorption enthalpy. These electronic changes had little effect on $\mathrm{CO}$ oxidation catalysis. The bimetallic catalysts were poor cyclohexene hydrogenation catalysts, indicating that there is relatively little exposed Pd when the catalyst is under hydrogen. These results suggest that the enhanced activity in $p$ chloronitrobenzene and 1,3-butadiene hydrogenation described in previous studies, which occurs without deleterious effects to the inherent selectivity of pure $\mathrm{Au}$ catalysts, arises from a combination of dilute surface $\mathrm{Pd}$ under hydrogenation conditions and an electronic modification of $\mathrm{Au}$ surface atoms by the incorporated Pd.

\section{AUTHOR INFORMATION}

\section{Corresponding Author}

*Phone: (210) 999-7557. Fax: (210) 999-7569. E-mail: Bert. chandler@trinity.edu.

\section{Present Addresses}

$\S$ (T.W.) Department of Chemistry, University of Georgia, Athens, GA 30602-2556.

${ }^{\perp}$ (R.H.) Petroleum and Geosystems Engineering Department, University of Texas at Austin, Austin, TX 78712-1585.

"(S.K.) Department of Physical Sciences, School of Science and Mathematics, Howard Payne University, Brownwood, TX 76801.

\section{Notes}

The authors declare no competing financial interest.

\section{ACKNOWLEDGMENTS}

The authors gratefully acknowledge the U.S. National Science Foundation (Grants Nos. CHE-1012395 and CHE-0449549) and the Welch Foundation (Departmental Grant No. W-0031) for financial support of this work. B.D.C. also thanks the Camille and Henry Dreyfus Foundation for support from a Henry Dreyfus Teacher-Scholar Award. The French team acknowledges the French "Agence Nationale de la Recherche" (ANR, reference ANR-11-JS07-0007) and the European COST program (COST-MP0903) for financial support.

\section{REFERENCES}

(1) Bond, G. C.; Louis, C.; Thompson, D. T. Catalysis by Gold; Imperial College Press: London, 2006; Vol. 6.

(2) Kung, M. C.; Davis, R. J.; Kung, H. H. J. Phys. Chem. C 2007, 111, 11767

(3) Corma, A.; Garcia, H. Chem. Soc. Rev. 2008, 37, 2096.

(4) Hashmi, S. K.; Hutchings Graham, J. Angew. Chem., Int. Ed. 2006, 45, 7896.

(5) Williams, W. D.; Shekhar, M.; Lee, W.-S.; Kispersky, V.; Delgass, W. N.; Ribeiro, F. H.; Kim, S. M.; Stach, E. A.; Miller, J. T.; Allard, L. F. J. Am. Chem. Soc. 2010, 132, 14018.

(6) Boucher, M. B.; Goergen, S.; Yi, N.; Flytzani-Stephanopoulos, M. Phys. Chem. Chem. Phys. 2011, 13, 2517.
(7) Deng, W.; Carpenter, C.; Yi, N.; Flytzani-Stephanopoulos, M. Top. Catal. 2007, 44, 199.

(8) Hutchings, G. J. J. Catal. 1985, 96, 292.

(9) Teles, J. H.; Brode, S.; Chabanas, M. Angew. Chem., Int. Ed. 1998, 37, 1415.

(10) Prati, L.; Rossi, M. J. Catal. 1998, 176, 552.

(11) Abad, A.; Concepcion, P.; Corma, A.; Garcia, H. Angew. Chem., Int. Ed. 2005, 44, 4066.

(12) Landon, P.; Collier, P. J.; Papworth, A. J.; Kiely, C. J.; Hutchings, G. J. Chem. Commun. 2002, 2058.

(13) Corma, A.; Serna, P. Science 2006, 313, 332.

(14) Cardenas-Lizana, F.; Gomez-Quero, S.; Hugon, A.; Delannoy, L.; Louis, C.; Keane, M. A. J. Catal. 2009, 262, 235.

(15) Hugon, A.; Delannoy, L.; Louis, C. Gold Bull. 2009, 42, 310.

(16) Jia, J.; Haraki, K.; Kondo, J. N.; Domen, K.; Tamaru, K. J. Phys. Chem. B 2000, 104, 11153.

(17) Segura, Y.; Lopez, N.; Perez-Ramirez, J. J. Catal. 2007, 247, 383.

(18) Han, Y. F.; Wang, J. H.; Kumar, D.; Yan, Z.; Goodman, D. W. J. Catal. 2005, 232, 467.

(19) Chen, M.; Kumar, D.; Yi, C.-W.; Goodman, D. W. Science 2005, $310,291$.

(20) Han, P.; Axnanda, S.; Lyubinetsky, I.; Goodman, D. W. J. Am. Chem. Soc. 2007, 129, 14355.

(21) Edwards, J. K.; Hutchings, G. J. Angew. Chem., Int. Ed. 2008, 47, 9192.

(22) Solsona, B. E.; Edwards, J. K.; Landon, P.; Carley, A. F.; Herzing, A.; Kiely, C. J.; Hutchings, G. J. Chem. Mater. 2006, 18, 2689.

(23) Edwards, J. K.; Solsona, B.; Ntainjua, N. E.; Carley, A. F.; Herzing, A. A.; Kiely, C. J.; Hutchings, G. J. Science 2009, 323, 1037.

(24) Edwards, J. K.; Solsona, B. E.; Landon, P.; Carley, A. F.; Herzing, A.; Kiely, C. J.; Hutchings, G. J. J. Catal. 2005, 236, 69.

(25) Enache, D. I.; Edwards, J. K.; Landon, P.; Solsona-Espriu, B.; Carley, A. F.; Herzing, A. A.; Watanabe, M.; Kiely, C. J.; Knight, D. W.; Hutchings, G. J. Science 2006, 311, 362.

(26) Gu, X.; Lu, Z.-H.; Jiang, H.-L.; Akita, T.; Xu, Q. J. Am. Chem. Soc. 2011, 133, 11822 .

(27) Kesavan, L.; Tiruvalam, R.; Ab Rahim, M. H.; bin Saiman, M. I.; Enache, D. I.; Jenkins, R. L.; Dimitratos, N.; Lopez-Sanchez, J. A.; Taylor, S. H.; Knight, D. W.; Kiely, C. J.; Hutchings, G. J. Science 2011, $331,195$.

(28) Hugon, A.; Delannoy, L.; Krafft, J.-M.; Louis, C. J. Phys. Chem. C 2010, 114, 10823.

(29) Kolli, N. E.; Delannoy, L.; Louis, C. J. Catal. 2013, 297, 79.

(30) Conte, M.; Carley, A. F.; Attard, G.; Herzing, A. A.; Kiely, C. J.; Hutchings, G. J. J. Catal. 2008, 257, 190.

(31) Hartshorn, H.; Pursell, C. J.; Chandler, B. D. J. Phys. Chem. C 2009, 113, 10718.

(32) Pursell, C. J.; Hartshorn, H.; Ward, T.; Chandler, B. D.; Boccuzzi, F. J. Phys. Chem. C 2011, 115, 23880.

(33) Long, C. G.; Gilbertson, J. D.; Vijayaraghavan, G.; Stevenson, K. J.; Pursell, C. J.; Chandler, B. D. J. Am. Chem. Soc. 2008, 130, 10103.

(34) Beakley, L.; Yost, S.; Cheng, R.; Chandler, B. D. Appl. Catal., A 2005, 292, 124

(35) Yi, C. W.; Luo, K.; Wei, T.; Goodman, D. W. J. Phys. Chem. B 2005, 109, 18535.

(36) Luo, K.; Wei, T.; Yi, C. W.; Axnanda, S.; Goodman, D. W. J. Phys. Chem. B 2005, 109, 23517.

(37) Gao, F.; Wang, Y.; Goodman, D. W. J. Phys. Chem. C 2010, 114, 4036.

(38) Pursell, C. J.; Chandler, B. D.; Manzoli, M.; Boccuzzi, F. J. Phys. Chem. C 2012, 116, 11117.

(39) Chandler, B. D.; Kendell, S.; Doan, H.; Korkosz, R. J.; Grabow, L. C.; Pursell, C. J. ACS Catal. 2012, 2, 684

(40) Chandler, B. D.; Long, C. G.; Gilbertson, J. D.; Vijayaraghavan, G.; Stevenson, K. J.; Pursell, C. J. J. Phys. Chem. C 2010, 114, 11498.

(41) Falsig, H.; Hvolboek, B.; Kristensen, I. S.; Jiang, T.; Bligaard, T.; Christensen, C. H.; Norskov, J. K. Angew. Chem., Int. Ed. 2008, 47, 4835 . 
(42) Nørskov and coworkers have proposed a similar mechanism based on DFT calculations (Falsig, , H.; Hvolboek, , B.; Kristensen, , I. S.; Jiang, , T.; Bligaard, , T.; Christensen, , C. H.; Norskov, , J. K. Angew. Chem. Int. Ed., 47,, 4835). The primary difference between Scheme 1 and the DFT results is the Scheme 1 assumes that the reaction between surface $\mathrm{O}$ atoms and adsorbed $\mathrm{CO}$ (the last step in the scheme) is fast. The DFT study found this last reaction step to be fast for Au catalysts and further found that direct reaction between surface bound $\mathrm{O} 2$ and adsorbed $\mathrm{CO}$ was required to accurately describe Au catalysts.

(43) Widmann, D.; Behm, R. J. Angew. Chem., Int. Ed. 2011, 50, 10241 .

(44) Aguilar-Guerrero, V.; Gates, B. C. Catal. Lett. 2009, 130, 108.

(45) Our first paper deriving and employing the Michaelis-Menten treatment used $\mathrm{KI}$ to describe $\mathrm{O}_{2}$ reactivity. On the basis of various feedback, we have changed the name of the constant to $K_{\mathrm{R}}$ so that it is not confused with a constant designed to describe inhibition.

(46) Saavedra, J.; Powell, C.; Panthi, B.; Pursell, C.; Chandler, B. J. Catal. 2013, 307, 37.

(47) Hugon, A.; Delannoy, L.; Louis, C. Gold Bull. 2008, 41, 127.

(48) Baber, A. E.; Tierney, H. L.; Sykes, E. C. H. ACS Nano 2010, 4, 1637.

(49) Rebelli, J.; Rodriguez, A. A.; Ma, S.; Williams, C. T.; Monnier, J.

R. Catal. Today 2011, 160, 170.

(50) Rebelli, J.; Detwiler, M.; Ma, S.; Williams, C. T.; Monnier, J. R. J.

Catal. 2010, 270, 224.

(51) Marx, S.; Baiker, A. J. Phys. Chem. C 2009, 113, 6191.

(52) Wei, X.; Yang, X.-F.; Wang, A.-Q.; Li, L.; Liu, X.-Y.; Zhang, T.;

Mou, C.-Y.; Li, J. J. Phys. Chem. C 2012, 116, 6222.

(53) Janssens, T. V. W.; Clausen, B. S.; Hvolbaek, B.; Falsig, H.; Christensen, C. H.; Bligaard, T.; Norskov, J. K. Top. Catal. 2007, 44, 15 .

(54) Jiang, T.; Mowbray, D. J.; Dobrin, S.; Falsig, H.; Hvolbaek, B.; Bligaard, T.; Norskov, J. K. J. Phys. Chem. C 2009, 113, 10548.

(55) Luo, K.; Wei, T.; Yi, C. W.; Axnanda, S.; Goodman, D. W. J.

Phys. Chem. B 2005, 109, 23517.

(56) Yi, C. W.; Luo, K.; Wei, T.; Goodman, D. W. J. Phys. Chem. B 2005, 109, 18535.

(57) Yuan, D. W.; Gong, X. G.; Wu, R. Q. Phys. Rev. B 2008, 78, 4.

(58) Wei, T.; Wang, J.; Goodman, D. W. J. Phys. Chem. C 2007, 111, 8781 .

(59) Gao, F.; Wang, Y.; Goodman, D. W. J. Am. Chem. Soc. 2009,

131,5734 .

(60) France, J.; Hollins, P. J. Electron Spectrosc. Relat. Phenom. 1993, $64-65,251$.

(61) Vannice, M. A.; Twu, C. C. J. Chem. Phys. 1981, 75, 5944.

(62) Vannice, M. A.; Wang, S. Y. J. Phys. Chem. 1981, 85, 2543.

(63) Yuan, D.; Gong, X.; Wu, R. Phys. Rev. B: Condens. Matter Mater. Phys. 2008, 78, 035441/1.

(64) Ponec, V. Appl. Catal., A 2001, 222, 31.

(65) Gao, F.; Wang, Y.; Goodman, D. W. J. Phys. Chem. C 2009, 113, 14993.

(66) Soto-Verdugo, V.; Metiu, H. Surf. Sci. 2007, 601, 5332.

(67) Vannice, M. A.; Chou, P. ACS Symp. Ser. 1986, 298, 76.

(68) Bus, E.; Prins, R.; van, B. J. A. Catal. Commun. 2007, 8, 1397.

(69) Ham, H. C.; Hwang, G. S.; Han, J.; Nam, S. W.; Lim, T. H. J.

Phys. Chem. C 2009, 113, 12943.

(70) Ham, H. C.; Hwang, G. S.; Han, J.; Nam, S. W.; Lim, T. H. J.

Phys. Chem. C 2010, 114, 14922.

(71) Ham, H. C.; Stephens, J. A.; Hwang, G. S.; Han, J.; Nam, S. W.;

Lim, T. H. J. Phys. Chem. Lett. 2012, 3, 566. 